\title{
Chronic Pancreatitis in Annular Pancreas, Presenting with Gastric Outlet Obstruction and Bile Duct Stricture
}

\author{
Ashok Kumar, Manas Agarwal, Nishant Malviya \\ Department of Surgical Gastroenterology, Sanjay Gandhi Postgraduate Institute of Medical Sciences, Lucknow-226014, \\ Uttar Pradesh, India.
}

\section{Corresponding Author: \\ Dr Ashok Kumar \\ Email: drashok97@gmail.com}

This is an Open Access article distributed under the terms of the Creative Commons Attribution License (creativecommons.org/ licenses/by/3.0).
Received
Accepted
March 29, 2020
Published
May 28, 2020
June 15,2020

\begin{abstract}
Background: Annular pancreas is an uncommon congenital entity. Its association with chronic pancreatitis, duodenal stenosis, and distal bile duct stricture in adult patient is extremely rare. Case Report: A 38 year female presented with on an off abdominal pain, nausea and vomiting for 4 months. Imaging revealed chronic pancreatitis with radiological distal common bile duct stricture. Endoscopic evaluation showed narrowing at second part of duodenum. A thin band of pancreas was encircling the second part of duodenum with other consistent radiological findings. Patient successfully managed by lateral pancreaticojejunostomy, stapler duodenoduodenostomy and Rouxen-Y hepaticojejunostomy. Conclusion: Stricture of distal bile duct and gastric outlet obstruction in chronic pancreatitis is not very uncommon but its association with annular pancreas is extremely rare. However, this entity can be successfully managed with high suspicion and proper evaluation.
\end{abstract}

Keywords: Annular Pancreas, Bile, Duodenal Obstruction, Nausea, Pancreatic Diseases, Vomiting.

\section{Introduction}

Annular pancreas is a very rare entity with incidence of $0.005 \%-0.015 \%$ in autopsy cases in adults [1]. It is associated with other congenital abnormalities eg. imperforate anus, malrotation of midgut, congenital heart disease, esophageal atresia and Down syndrome. A thin band of pancreas encircles second part of duodenum partially or completely and symptoms usually relate with degree of obstruction. Most of cases present in early life with complain of gastric outlet obstruction, in some cases symptom appear after establishment of inflammation of annulus pancreas in associated chronic pancreatitis. Abdominal pain was most common symptom; it's seen in about $2 / 3^{\text {rd }}$ of all adult patients of annular pancreas, followed by nausea, vomiting and rarely hematemesis [2]. Here we report a case of annular pancreas associated with chronic pancreatitis presenting with gastric outlet obstruction, bile duct stricture which was successfully managed surgically by lateral pancreaticojejunostomy, stapler duodenoduodenostomy and Roux-en-Y hepaticojejunostomy.

\section{Case Report}

A 38 year female presented with complains of sudden onset, severe, recurrent epigastric pain for 10-12 years. The pain was radiating towards back, aggravated on food intake and relieved only on parenteral analgesics. Pain was also associated with nausea and occasional, small volume, non bilious vomiting. Initially frequency was once in 4-5 months which increased up to 2-3 episodes every month. There was no history of jaundice, gastrointestinal bleed, altered bowel habits, significant weight loss 
and past surgery. There was also no suggestive history of exocrine or endocrine insufficiency. Past history of anti-tubercular treatment in 2002 was elicited. On examination patient was average built and well nourished and oriented, ECOG score was 0, BMI 27.2. Chest and abodmen examination were unremarkable. Hemogram and liver function tests were unremarkable.

\section{Abdominal ultrasonography}

demonstrated normal liver, no intra-hepatic biliary dilatation, gall bladder (GB) was distended with no calculus, $7.3 \mathrm{~mm}$ dilated common bile duct (CBD), calcific foci in head of pancreas, size and echo-texture of pancreas was normal. CECT abdomen shows normal CBD, multifocal small calcifications in head and neck region of pancreas with atrophy of body and tail representing chronic calcific pancreatitis with main pancreatic duct (MPD) dilatation [Fig.1]. MRCP also confirmed the finding of atrophic pancreas, $8.1 \mathrm{~mm}$ MPD dilatation in whole length with involvement of side branches mild to moderate bilateral IHBRD, CBD dilated up to $12.4 \mathrm{~mm}$ with smooth distal tapering, no intra-luminal filling defects, impression was stricture lower CBD. Upper GI endoscopy showed huge dilatation of first part of duodenum (D1) due to partial stricture of second part of duodenum (D2) with finding of food stasis or pooling of secretions. Scope was coiling within dilated D1 and could not pass beyond D2. In view of partial gastric outlet obstruction, failed D2 negotiation dilated MPD and CBD stricture patient was planned for surgical management. Per-operatively there were flimsy adhesions between posterior wall of stomach and pancreas. A thin streak of annular pancreas was encircling D2, compromised lumen diameter [Fig.2], pancreas was found atrophic and firm, MPD was mildly dilated, no stricture present, single stone of $1 \mathrm{~cm}$ in MPD near head region with sludge present. Spleen was normal in size, no obvious collaterals. Pancreatic duct was opened, stone removed, head coring of pancreatic, and cholecystectomy performed as a part of

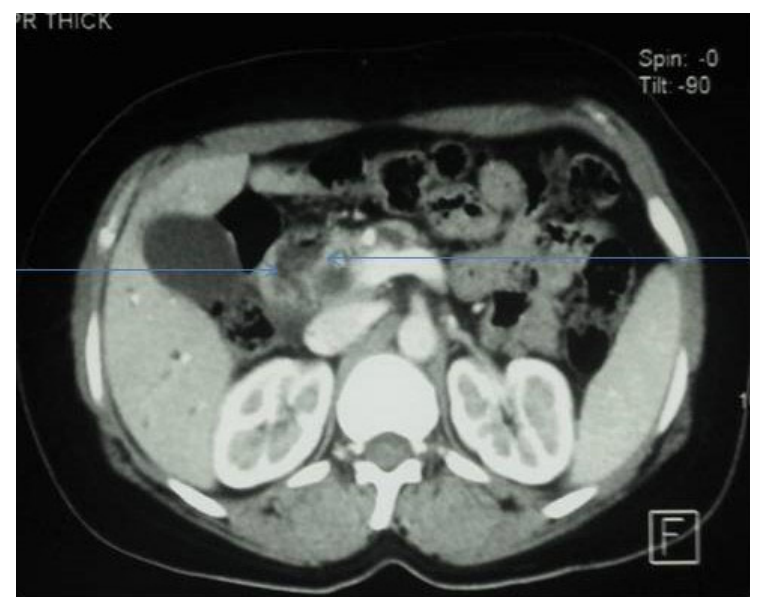

Fig.1: Thin band of annnular pancreas and distended first part of duodenum.

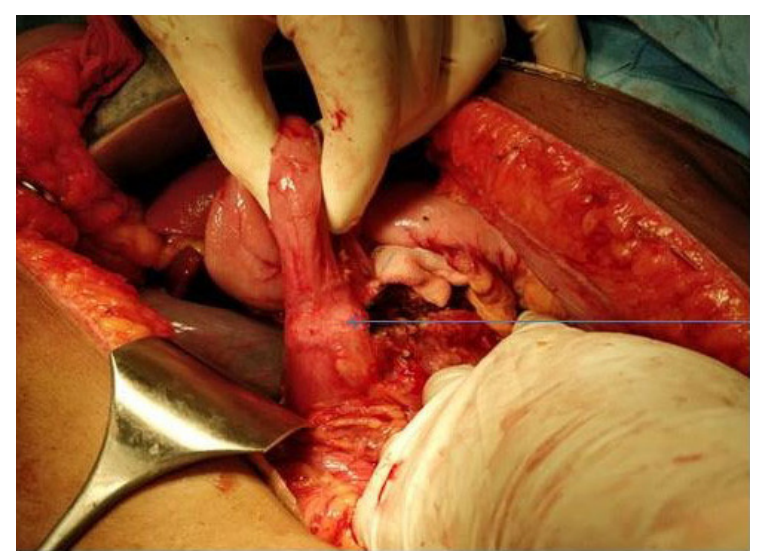

Fig.2: A steak of pancreas encircling the second part of duodenum.

procedure. Duodenum mobilized enough and side to side stapler duodenoduodenostomy done by firing of NTLC 75 and duodenostomy closed with 2 layer of prolene 3-0 [Fig.3]. Side to side single layer, continuous interlocking Roux-en-Y lateral pancreaticojejunostomy (LPJ) with prolene 3-0 and side to side Roux-en-y hepaticojejunostomy $20 \mathrm{cms}$ distal to LPJ done with PDS 5-0 in diamond shaped configuration. Specimen shows normal GB mucosa with no stones. Final histopathology was chronic calcific pancreatitis with chronic cholecystitis. Post-operative period was uneventful, abdominal drain removed on $2^{\text {nd }}$ post-operative day, patient 
discharged on $4^{\text {th }}$ post-operative day with advice of follow up. On last 2 years follow up she has asymptomatic

\section{Discussion}

Annular pancreas is very rare congenital anomaly which has been reported $0.005 \%-0.015 \%$ in autopsy study of adults [2]. Regarding etiopathogenesis there are two hypotheses first, adhered tip of right ventral bud duodenal wall stretches and form a complete ring during normal rotation [3] and according to second hypothesis, persistent ventral bud develops a complete circle of pancreatic tissue around duodenum [4]. Annular pancreas may associate with other pathological conditions like peptic ulcer, acute and chronic pancreatitis, pancreaticolithiasis, and duodenal obstruction carcinoma head of pancreas with biliary obstruction and gastric outlet obstruction. Association of annular pancreas with acute pancreatitis was most commonly seen in adults in comparison to younger age group patients [5-7]. About $75 \%$ of acute pancreatitis involves second part of duodenum followed by first and third part of duodenum in rest $25 \%$ of cases. Pancreatitis in annular pancreas usually involves annulus and adjoining area of head and body, tail of panaceas is usually preserved [8].

In most cases, the initial ultrasonography or upper gastrointestinal double contrast studies may help to approach the diagnosis which usually shows the classical double bubble sign in presence of duodenal obstruction. Non invasive investigations like CT scan and MRI with MRCP may reveals normal or inflamed encircling pancreatic tissue around duodenum [9]. An upper gastrointestinal endoscopy may reveal a concentric duodenal narrowing mostly on second part and pre-stenotic dilation of first part of duodenum. There are only few reports which has been shown valuable role of endoscopic ultrasonography in the diagnosis of annular panaceas [10]. Initial acute pancreatitis and associated duodenal obstruction is managed by

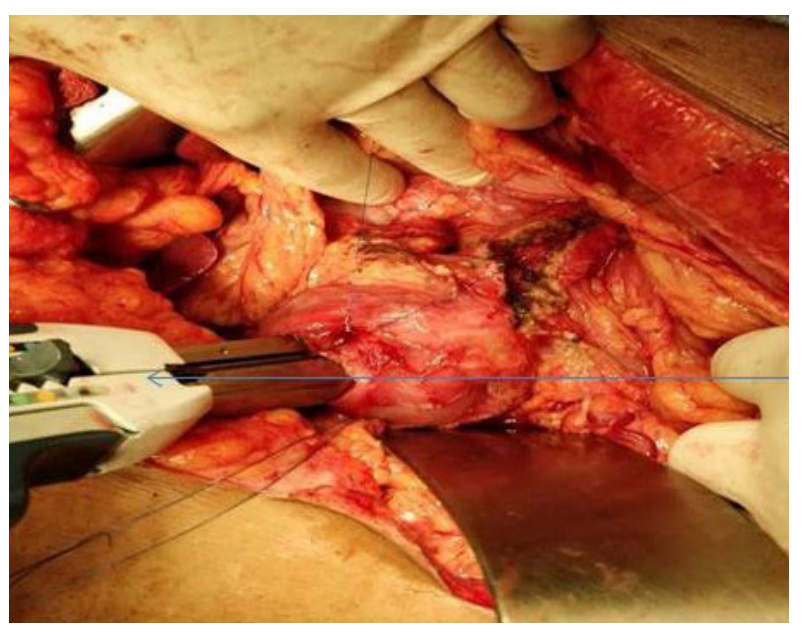

Fig.3: Open pancreatic duct with side duodeno-duodenostomy with 75 mm linear NTLC stapler.

medical treatment, however, in case of unrelieved duodenal obstruction or failed medical treatment, several bypass procedures proposed in form of gastrojejunostomy or duodenojejunostomy are used to relief the persistent duodenal obstruction. It is extremely difficult to remove the annular ring of pancreatic tissue since the pancreatic tissue may lie intra-murally with difficult dissection plane [11].

Here in our case patient presented with suggestive history of chronic pancreatitis for 12 years and occasional symptoms of partial gastric outlet obstruction which was documented on upper GI endoscopy. However, annular pancreas as a cause of obstruction found during surgery and patient treated surgically by lateral pancreaticojejunostomy, stapler duodenodudenostomy and Roux en y hepaticojejunostomy in view of distal CBD stricture on MRCP has been rarely reported.

\section{Conclusion}

Annular pancreas is rare entity and its association with chronic pancreatitis is extremely rare. Annular pancreas and its association with chronic pancreatitis is difficult to diagnose pre-operatively, however, this entity could successfully managed by high suspicion and proper evaluation in a specialized department. 
Contributors: AK was responsible for the writing the manuscript and patient management; MA, NM were responsible for critical revision of manuscript and patient management. AK will act as a study guarantor. All authors approved the final version of this manuscript and are responsible for all aspects of this study.

Funding: None; Competing interests: None stated.

\section{References}

1. Ravitch MM, Woods Jr AC. "Annular pancreas". Ann Surg. 1950;132:1116-1127.

2. Newman BM, Lebenthal E, Gardner JD. Congenital abnormalities of the exocrine pancreas. In: BLW. Go, JD Gardner, F.P. Brooks (eds.), Raven Press, New York, 1986:pp.773-782.

3. Lecco T.M. "Zur morphologie des pankreas annulare" Sitzungsberichte der Heidelberger Akademieder Wissenschaften. 1910;119:391-406.

4. Baldwin WA. "A specimen of annular pancreas". The Anatomical Record. 1910;299-304.

5. Faerber EN, Friedman AC, Dabezies MA. Annular
Pancreas. In: Friedman AC, Dachman AH (eds.). Annular pancreas. Radiology of the Liver, Biliary Tract, Pancreas, Mosby-Year Book, St. Louis, MO. 1994;pp.745-748.

6. Beachley MC, Lankau CA. Symptomatic adult annular pancreas. Am J Dig. 1973;18:513-516.

7. Beduya D, Nir I, Parasher G. A 50-year-old man with post-pandrial epigatsric pain. Dig Dis Sc. 2014;59:26532655.

8. Jarry J, Wagner T, Rault A, Cunha Sa, Collet D. Annular pancreas: a rare cause acute pancreatitis. J Pancreas. 2011;12:155-157.

9. Choi JY, Kim MJ, Kim JH, Lim JS. Annular pancreas: emphasis on magnetic resonance cholangiopancreatography findings. J Comput Assisted Tomogr. 2004;28:528-532.

10. Papachristou GI, Topazian MD, Gleeson FC, Levy MJ. EUS features of annular pancreas. Gastrointest Endosc. 2007;65:340-334.

11. Ravitch MM, Woods AC Jr. Annular pancreas. Ann Surg. 1950;132:1116-1127. 